This is the final peer-reviewed accepted manuscript of:

C. Santoro, F. Soavi*, A. Serov, C. Arbizzani, P. Atanassov*, Self-Powered Supercapacitive Microbial Fuel Cell: The Ultimate Way of Boosting and Harvesting Power, Biosensors and Bioelectronics, 78 (2016) 229-235.

The final published version is available online at: https://doi.org/10.1016/i.bios.2015.11.026

Rights / License:

The terms and conditions for the reuse of this version of the manuscript are specified in the publishing policy. For all terms of use and more information see the publisher's website.

This item was downloaded from IRIS Università di Bologna (https://cris.unibo.it/)

When citing, please refer to the published version. 


\section{Self-Powered Supercapacitive Microbial Fuel Cell: The Ultimate Way of Boosting}

2 and Harvesting Power

3

4 Carlo Santoro ${ }^{\mathrm{a}, \dagger}$, *Francesca Soavi ${ }^{\mathrm{b}, \dagger}$, Alexey Serov ${ }^{\mathrm{a}}$, Catia Arbizzani ${ }^{\mathrm{b}}$, **Plamen $5 \quad$ Atanassov $^{\mathrm{a}}$

6

$7{ }^{\text {a }}$ Department of Chemical \& Biological Engineering, Center for Micro-Engineered 8 Materials (CMEM), University of New Mexico, Albuquerque, NM 87131, USA.

9 b Department of Chemistry “Giacomo Ciamician”, Alma Mater Studiorum - Università di 10 Bologna, Via Selmi, 2, 40126 Bologna, Italy.

\section{Corresponding authors:}

13 * Francesca Soavi, Department of Chemistry Giacomo Ciamician, Alma Mater 14 Studiorum- Università di Bologna, Via Selmi, 2, Bologna, Italy, e-mail:

15 francesca.soavi@unibo.it

16

$17 * *$ Plamen Atanassov, Department of Chemical \& Biological Engineering, Center for 18 Micro-Engineered Materials (CMEM), University of New Mexico, Albuquerque, NM 19 87131, USA, e-mail: plamen@,unm.edu

20

$21 \dagger$ The two authors have contributed equally to the manuscript 


\section{Abstract}

26 In this work, for the first time, we demonstrate a supercapacitive microbial fuel cell

27 which integrates the energy harvesting function of a microbial fuel cell (MFC) with the

28 high power operation of an internal supercapacitor. The pursued strategies are: i) the

29 increase of the cell voltage by the use of high potential cathodes like bilirubin oxidase

30 (BOx) or iron-aminoantipyrine (Fe-AAPyr); ii) the use of an additional capacitive

31 electrode (additional cathode, AdC) which is short-circuited with the MFC cathode and

32 coupled with the MFC anode (MFC-AdC). The high working potential of BOx cathode

33 and the low impedances of the additional capacitive electrode and the MFC anode

34 permitted to achieve up to $19 \mathrm{~mW}\left(84.4 \mathrm{Wm}^{-2}, 152 \mathrm{Wm}^{-3}\right)$, the highest power value ever

35 reported for MFCs. Exploiting the supercapacitive properties of the MFC electrodes

36 allows the system to be simpler, cheaper and more efficient without additional electronics

37 management added with respect to an MFC/external supercapacitor coupling. The use of

38 the AdC makes it possible to decouple energy and power and to achieve recharge times in

39 the order of few seconds making the system appealing for practical applications.

41 Keywords: microbial fuel cell, supercapacitor, additional cathode, EDLC, high 42 current/power 
45 Microbial fuel cell (MFC) is a promising biotechnology for multiple applications such as

46 wastewater treatment and energy production from organic compounds (Rinaldi et al., 47 2008). Enhancement of MFCs performance through anode and cathode electrodes 48 materials development has been the main focus of the past decade for the scientists all 49 over the world (Rinaldi et al., 2008). In general, MFCs can be based on anodes made of 50 carbonaceous (Wei et al., 2011) and not carbonaceous electro-conductive materials

51 (Pocaznoi et al., 2012; Guerrini et al., 2014). Anodes feature high surface area in order to 52 accommodate electroactive bacteria that degrade organics and transfer electrons through

53 an external load. On the other side, cathode catalysts can be from different families of: i) 54 carbonaceous high surface materials (Watson et al. 2013), ii) platinum-based materials 55 (Liu et al., 2015), iii) non-platinum based materials (Antolini, 2015), iv) enzymatic 56 (Schaetzle et al., 2009; Higgins et al. 2011), and v) microbial (Jang et al., 2013; Ishii et 57 al. 2014). Such organic/inorganic materials as well as biotic matter work as catalysts or 58 co-catalyst enhancing the oxygen reduction rate and complete the redox reaction of the

59 MFC. It has been previously shown that at neutral working $\mathrm{pH}$, enzymes (bilirubin 60 oxidase and laccase) based catalysis posses the highest open circuit potentials (OCPs) 61 among the existing catalysts for oxygen reduction reaction (ORR) (Mano et al., 2003;

62 Soukharev et al., 2004).

63 Current/power generated from MFC systems is over 3 orders of magnitude lower 64 compared to traditional hydrogen- or methanol-fuelled FC (Logan and Rabaey, 2012) and 65 therefore a smart design is necessary in order to harvest the low energy produced and for 
66 the subsequent delivering of the high power pulses which are required for powering

67 devices. Supercapacitors are electrochemical energy storage systems which deliver high

68 specific power (up to $10 \mathrm{~kW} \mathrm{~kg}^{-1}$ ) at required energy levels (Conway, 1999).

69 Electrochemical double layer capacitors (EDLC) use high surface area carbon electrodes

70 that store/deliver charge by an intrinsically fast and highly reversible electrostatic process

71 (Béguin et al., 2014).

72 Supercapacitors have been externally combined to the MFCs in order to harvest

73 appropriately the energy of the system. The external supercapacitors are recharged by the

74 MFCs and provide high power output during the discharge. This combination has been

75 already investigated by several groups (Wang et al.; 2015). The smart design and

76 efficient series/parallel connection of MFCs with external supercapacitors allowed to

77 power small electronics devices (Papaharalabos et al., 2013, 2014), sensors (Donovan et

78 al., 2011, 2013; Di Lorenzo et al., 2014; Ewing et al., 2014; Dewan et al., 2014; Park et

79 al. 2012), a mobile phone (Ieropoulos et al., 2013), robotics prototypes (Ieropoulos et al.,

$802005,2010,2012)$ and the pump required to manage the wastewater flow in MFCs

81 (Ledezma et al., 2013).

82 The size of the supercapacitor to be connected with the MFC is a crucial design point.

83 Indeed, the commercially available EDLCs with capacitance on the order of Farads

84 require a substantial recharging time (on the order of several min or even hours) at the

85 low current regimes of MFCs (on the orders of $\mu \mathrm{A}$ ). Every generated high current/power

86 pulse requires a long time before its repetition, and consequently the tool that is powered

87 by the MFC/external EDLC is switched on periodically, with long standby steps. 
88 The capacitive behavior of the MFC anode has been recently investigated (Deeke et al., 89 2012; Feng et al., 2012). It has been also reported an MFC anode decoration with 90 ruthenium oxide to improve the capacitive response of MFCs (Lv et al., 2012) but its

91 high cost prevents the usage in large scale MFCs.

92 Designing and improving the capacitive response of the MFC electrodes is a challenging

93 task for creating an integrated MFC-internal supercapacitor system. The capacitive

94 electrodes are expected to accomplish high power discharges, being simultaneously

95 recharged by the MFC redox reactions taking place at the electrode/organics containing 96 solution and electrode $/ \mathrm{O}_{2}$ interfaces.

97 This approach has been already exploited in the field of biofuel cells where the first use 98 of enzymatic biofuel cells (BFC) as internal supercapacitor was recently demonstrated by 99 Pankratov et al. (2014a; 2014b). In this case, the high surface area, carbonaceous anode 100 and cathode of the BFC operated as the electrodes of the supercapacitor. Higher 101 performances have been recently obtained by Agnès et al. (2014) using a glucose-oxygen 102 enzymatic biofuel cell with maximum open circuit voltage of $\approx 800 \mathrm{mV}$. The BFC103 supercapacitor hybrid system had the highest power achieved of approximately $18 \mathrm{~mW}$ 104 (Agnès et al., 2014).

105 To our best knowledge, for the first time, in this study we report on supercapacitive 106 MFCs where anode and cathode simultaneously harvest energy from wastewater and 107 work as self-powered EDLC. The power delivered by supercapacitors increases with cell 108 voltage and with the decrease of the equivalent series resistance (ESR). We demonstrate 109 how the power output of the MFC can be dramatically improved by two strategies: i) the 110 use of non-platinum group metal, like iron-aminoantipyrine (Fe-AAPyr) and of bilirubin 
111 oxidase (BOx) cathodes to increase cell voltage, and ii) the usage of a third, capacitive

112 electrode based on high surface area carbon to decrease ESR. The latter is an "additional

113 cathode" (AdC) which is short-circuited with the MFC cathode and is coupled with the

114 MFC anode to give a self-powered supercapacitor (MFC-AdC). This is the first time that

115 the concept of AdC electrode is used. The proof-of-concept is demonstrated using a

116 commercial high surface area carbon brush as the additional cathode and by galvanostatic

117 tests at different currents from $1 \mathrm{~mA}$ up to $45 \mathrm{~mA}$.

118

119 2. Materials and Methods

120

\section{$121 \quad 2.1$ MFC configuration and electrolyte composition}

123 Single glass bottle MFC (Cataldo Arbore, Milan, Italy) with $125 \mathrm{~mL}$ volume was used. A

124 lateral hole of $2.25 \mathrm{~cm}^{2}$ allowed the insertion of the cathode that was there screwed using 125 a metallic clamp. Membraneless configuration allowed the exposure of anode and

126 cathode to the same electrolyte. A reference electrode $(\mathrm{Ag} / \mathrm{AgCl} 3 \mathrm{M} \mathrm{KCl})$ was included

127 for the basic electrochemical studies.

128 The electrolyte was composed of a mixture of $50 \%$ volume of activated sludge from

129 Albuquerque Southeast Water Reclamation Facility (New Mexico, USA) and 50\%

130 volume of phosphate buffer saline solution (PBS) and $\mathrm{KCl}$ 0.1M. PBS was made using

$131 \mathrm{KH}_{2} \mathrm{PO}_{4}(1.77 \mathrm{~g})$ and $\mathrm{K}_{2} \mathrm{HPO}_{4}(15.16 \mathrm{~g})$. The $\mathrm{pH}$ of the electrolyte was $7.5 \pm 0.02$. An air

132 breathing cathode configuration was used and the tests were run in ambient conditions.

133 The experiments have been carried out in Albuquerque at a constant temperature that was 
$13422 \pm 1{ }^{\circ} \mathrm{C}$ and at 1600 meters above sea level. At that altitude, oxygen concentration is

135 roughly $20 \%$ lower compared to sea level due to the lower air pressure. This parameter

136 has to be taken into account when comparing the performance of air-breathing MFCs.

137

$138 \quad 2.2$ MFC electrode materials and additional cathode material

140 Anode electrodes were based on a carbon brush (Millirose, USA) of diameter $3 \mathrm{~cm}$,

141 length of $3 \mathrm{~cm}$ and projected area of $9 \mathrm{~cm}^{2}$. The anodes were pre-colonized by mixed

142 cultures bacteria taken from previous experiments running for over 4 months (Santoro et

143 al., 2015a). Three different cathodes based on activated carbon (AC), iron-

144 aminoantipyrine (Fe-AAPyr) and bilirubin oxidase (BOx) enzymes were used. All the

145 cathodes tested had the same current collector that was metallic stainless steel mesh

146 (McMaster, USA).

147 AC-based cathode was prepared by mixing 70\%wt high surface area AC (Norit SX Ultra,

148 Sigma Aldrich), 10\%wt carbon black (CB, Alfa Aesar) and 20\%wt PTFE (60\% solution,

149 Sigma Aldrich) for $5 \mathrm{~min}$ in a coffee grinder. The carbon black was added to enhance the

150 composite electrode conductivity. After mixing, the composite material was pressed at 2

$151 \mathrm{mT}$ into a pellet die for $5 \mathrm{~min}$ (Santoro et al., 2014). The composite loading was $35 \pm 5 \mathrm{mg}$

$152 \mathrm{~cm}^{-2}$, the geometric area was $2.25 \mathrm{~cm}^{2}$ and this value was used for the power

153 normalization. The cathode has not been heated as previously shown (Santoro et al.,

154 2014). The volume used for power normalization refers to the chamber volume of 125

$155 \mathrm{~mL}$. 
156 The same procedure was followed to prepare Fe-AAPyr based cathode except that Fe-

157 AAPyr was added into the mixture and mixed vigorously, before pressing at $2 \mathrm{mT}$. The

158 preparation of Fe-AAPyr has been previously described (Santoro et al., 2015b). The Fe-

159 AAPyr loading was $1.5 \pm 0.1 \mathrm{mg} \mathrm{cm}^{-2}$. Synthetic approach for preparation of Fe-AAPyr

160 was based on Sacrificial Support Method developed at University of New Mexico. (Serov

161 et al., 2014a, 2014b)

162 The preparation of BOx cathode instead was based on $\mathrm{AC}(70 \% \mathrm{wt}), 10 \% \mathrm{wt} \mathrm{CB}$ and

$16320 \%$ wt PTFE ground for $5 \mathrm{~min}$ and then pressed at $2 \mathrm{mT}$ for $5 \mathrm{~min}$. After that,

164 isopropanol $\left(40 \mu \mathrm{L} \mathrm{cm}^{-2}\right)$ was added on the top to create a hydrophilic/hydrophobic

165 gradient. A multi-walled nanotube paper (MWNTP, Buckeye Composite) was then fused

166 together on the top using pressure $0.25 \mathrm{mT}$ for $5 \mathrm{~min}$ ). At last, $10 \mathrm{mg}$ of BOx (Amano

167 Enzyme, USA) dissolved in $50 \mathrm{mM}$ PBS solution was then drop-casted onto the MWNTP

168 surface. The cathodes were kept at $4^{\circ} \mathrm{C}$ over night for enzyme immobilization. Before the

169 utilization, the liquid was dried and then the cathode was screwed on the lateral hole of

170 the bottle (Santoro et al., 2013).

171 The additional cathode for the supercapacitor was carbon brush (Millirose, USA) of

172 diameter $2 \mathrm{~cm}$ and projected area of $4 \mathrm{~cm}^{2}$ that was coated with a 95\%wt AC- 5\%wt

173 Nafion layer ( $0.3 \mathrm{~g}$ total). The carbon brush was immersed into a solution based on

174 Nafion (0.5\% alcoholic solution Dupont, $1.0 \mathrm{~mL}), \mathrm{AC}(100 \mathrm{mg})$ and water-isopropanol

175 solution $(1 \mathrm{~mL})$ and then was dried in ambient atmosphere over night. The addition of

$176 \mathrm{AC}$ allowed the increase in surface area of the carbon brush and consequently in the

177 capacitance of the overall additional cathode brush. The additional cathode was

178 completely immersed into the electrolyte and short-circuited with the MFC cathode. 


\subsection{Electrochemical measurements}

182 Electrochemical measurements have been done using a potentiostat (SP-50, Bio-Logic,

183 France). Electrochemical tests consisted in the repetition of a sequence of the following 184 steps: rest $(\mathrm{OCV})$ - galvanostatic (GLV) discharge at different currents ( $\left.\mathrm{i}_{\text {pulse }}, \mathrm{A}\right)$ from 1

$185 \mathrm{~mA}$ up to $45 \mathrm{~mA}$ ) over $10 \mathrm{~ms}, 2 \mathrm{~s}$ or complete discharge down to $0 \mathrm{~V}$ cell voltage. The 186 use of the reference electrode permitted to simultaneously monitor the MFC anode and 187 cathode (eventually short circuited with the AdC cathode) potentials as well as the cell 188 voltage during the sequence repetition. The analysis of the GLV discharge data is detailed 189 in the ESI section

\section{3. Results and discussion}

\subsection{Supercapacitive Microbial Fuel Cell}

\section{PLEASE INSERT HERE FIGURE 1}

197 In rest conditions, the cell voltage $\left(\mathrm{V}_{\max }\right.$, OC) of an MFC is determined by the equilibrium 198 potentials of the half-reactions taking place at the electrodes. The anaerobic anode 199 equilibrium potential of acetate oxidation at $\mathrm{pH}=7$ is equal to $\sim-500 \mathrm{mV}$ vs $\mathrm{Ag} / \mathrm{AgCl}$. The 200 theoretical potential for the oxygen reduction reaction at $\mathrm{pH}=7$ is $\sim 620 \mathrm{mV}$ vs $\mathrm{Ag} / \mathrm{AgCl}$ 201 (Erable et al., 2012). The anaerobic (bio-anode) and aerobic (cathode) environments of 
202 the MFC polarize the carbon electrodes towards values that are more negative and 203 positive than the typical equilibrium potential (near $0 \mathrm{mV}$ vs $\mathrm{Ag} / \mathrm{AgCl}$ (Béguin et al., 204 2014)) exhibited by metal and catalyst-free carbons in the de-aerated electrolytes (e.g. 205 supercapacitors electrolytes). The electrode processes cause the formation of 206 electrochemical double layers at the MFC electrode/electrolyte interfaces (Conway, 207 1999).

208 The excess of negative and positive charges, at the polarized anode and cathode surfaces

209 respectively, is balanced by positive and negative counter ions coming from the ionic 210 species dissolved in the solution. Electrolyte ions migrate to oppositely charged 211 electrodes forming an electrochemical double layer at each high-surface area 212 carbonaceous electrode of the MFC. The MFC is electrostatically storing charge at $213 \mathrm{~V}_{\max , \mathrm{OC}}$, hence it is storing energy like in the case of an EDLC. The MFC anode and 214 cathode can be then discharged by a rapid electrostatic process. Their surface charges are 215 neutralized and ions are released in the bulk wastewater solution. The energy that was 216 electrostatically stored can thus be delivered by high and short galvanostatic discharge 217 pulses (GLV) and high power output is achieved. Subsequent rest, i.e. setting the MFC in 218 OC without any external load applied, restores the electrode equilibrium potentials. The 219 carbon electrodes are polarized again, the double-layers at each electrode are re220 established, and the internal EDLC is recharged. Under these conditions, the system 221 operates a self-powered supercapacitor (Fig. 1.a and Fig. 1.b).

222 Fig. 1.c reports the cell voltage trend of a MFC under a rest (OC) - galvanostatic 223 discharge pulse (GLV) - OC sequence. Fig. 1.c also highlights the parameters that were

224 used for the evaluation of the system performance (see Supplemental Information). 
PLEASE INSERT HERE FIGURE 2

228 For the first time, this concept was proven by the data reported in Figure 2 that shows the

229 MFCs cell voltage and electrode potential profiles under the sequence test reported in

230 Fig. 1.c, by $2 \mathrm{~s}$ ( $\mathrm{t}_{\text {pulse }}$ ) discharge pulse at $3 \mathrm{~mA}$ (i $\mathrm{i}_{\text {pulse }}$ ). The MFCs investigated had

231 different cathodes described before as AC, Fe-AAPyr and BOx and the cells are labeled

232 with the cathode acronyms. The AC, Fe-AAPyr and BOx MFCs features $\mathrm{V}_{\max }$, OC of 590

$233 \mathrm{mV}, 650 \mathrm{mV}$ and $790 \mathrm{mV}$, respectively. This trend follows the equilibrium cathode

234 potentials of 105,175 and $315 \mathrm{mV}$ vs $\mathrm{Ag} / \mathrm{AgCl}$ for $\mathrm{AC}, \mathrm{Fe}-\mathrm{AAPyr}$ and $\mathrm{BOx}$ cathodes.

235 Higher cathode potentials of BOx compared to other catalysts have been previously

236 shown (Mano et al., 2003). In all the investigated MFCs the equilibrium anode potential

237 was $\approx-500 \mathrm{mV}$ vs $\mathrm{Ag} / \mathrm{AgCl}$ which is close to the theoretical value.

238 The pulse caused the decrease of $V_{\max }$, OC by ohmic $\left(\Delta \mathrm{V}_{\text {ohmic }}\right)$ and capacitive $239\left(\Delta \mathrm{V}_{\text {capacitive }}\right)$ contributions (Fig. 1.c). The $\Delta \mathrm{V}_{\text {ohmic }}$ cell voltage losses were in the range of

$240311 \mathrm{mV}$ to $383 \mathrm{mV}$ (Fig. 2 a,c,e) which were due to ESRs of 105-130 $\Omega$ (Table S1,

241 calculation in SI). Monitoring the MFC electrode potentials during the pulse permitted to

242 identify the cathode as the main contributor of $\Delta \mathrm{V}_{\text {ohmic }}$ and, hence, of ESR for all the

243 MFCs (Fig. 2.b,d,f). Cathode overpotentials at $\mathrm{i}_{\text {pulse }}$ equal to $3 \mathrm{~mA}$ were $299 \mathrm{mV}$ for BOx,

244 followed by Fe-AAPyr with $339 \mathrm{mV}$ and AC with $344 \mathrm{mV}$ and accounted for over $90 \%$

245 of the total MFC $\Delta \mathrm{V}_{\text {ohmic }}$ and ESR. The high electrode thickness $(\approx 1 \mathrm{~mm})$ that is required

246 to avoid wastewater leakage through the breathing cathode could be one of the

247 parameters that determine the high cathode impedances (in the order of $100 \Omega$, as 
248 evaluated by dividing the cathode overpotential by $\left.\mathrm{i}_{\text {pulse }}\right)$. The lowest ohmic losses of

249 BOx cathode can be related to the utilization of CNT in the electrode preparation. CNT 250 enhanced electronic conductivity compared to AC-based electrodes. The anodes based on

251 carbon brush colonized by electro-active bacteria featured very low overpotentials within

252 few $\mathrm{mV}$ (accounted for less than $10 \%$ of the total MFC $\Delta \mathrm{V}_{\text {ohmic }}$ and ESR). This suggests

253 that using high surface area and high conductivity carbon brush contributed to very low

254 anode impedance that varied in a small range of $4-13 \Omega$.

255 For all the MFCs, the $\Delta \mathrm{V}_{\text {capacitive }}$ cell voltage loss of the different MFCs was negligible 256 and similar, indicating comparable cell capacitance (C) response. The values of $\mathrm{C}$ 257 estimated by the cell voltage slope (s) (Conway, 1999) were between 80 and $100 \mathrm{mF}$ 258 (Table S1, calculation in SI). The electrode profile analyses indicated that anode and 259 cathode almost equally contribute to $\mathrm{C}$ with electrode capacitances of ca. $200 \mathrm{mF}$.

260 Capacitance (C), equivalent series resistance (ESR), and maximum cell voltage under 261 operation $\left(\mathrm{V}_{\max }\right)$, which in turn depends on ESR (see SI), determine the practical 262 maximum energy $\left(\mathrm{E}_{\max }\right)$ and power $\left(\mathrm{P}_{\max }\right)$ and the charge/discharge time constant $(\tau)$ of

263 the supercapacitor. Indeed, these parameters are related by the following equations:

$264 \quad \mathrm{E}_{\max }=1 / 2 \mathrm{C} \times \mathrm{V}_{\max }{ }^{2}$

$265 \mathrm{P}_{\max }=\mathrm{i}_{\text {pulse }} \times \mathrm{V}_{\max }$

$266 \tau=\mathrm{ESR} \times \mathrm{C}$.

$267 \mathrm{C}$ and ESR were used to estimate $\tau$ (Table S1) which was in the order of $10 \mathrm{~s}$, thus 268 demonstrating the fast rate capability of the supercapacitive system. Table S1 reports the 269 practical values of $E_{\max }$ and $P_{\max }$, and of the useful energy delivered during the pulse 270 (E $\left.\mathrm{E}_{\text {pulse }}\right)$ and average pulse power $\left(\mathrm{P}_{\text {pulse }}\right)$ evaluated by the GLV curves at $3 \mathrm{~mA}$ reported on 
271 Fig. 2. These values were calculated by taking into account that the highest feasible cell

272 voltage $\left(\mathrm{V}_{\max }\right)$ is the voltage of the charged cell in open circuit conditions $\left(\mathrm{V}_{\max }, \mathrm{oc}\right)$

273 decreased by $\Delta V_{\text {ohmic }}$ after the pulse (see Figure 1.c), which in turn depends on $i_{\text {pulse }}$ (eqs.

274 SI9 and SI10). The energy and power values increase in the order AC $<$ Fe-AAPyr $<$

275 BOx, thus following the MFC voltage trend.

276

\section{PLEASE INSERT HERE FIGURE 3}

279 On the basis of $\Delta \mathrm{V}_{\text {ohmic }}$ and ESR that were evaluated by the test reported in Fig. 2, we 280 calculated the $\mathrm{P}_{\max }$ that can be delivered by the three MFCs at different $\mathrm{i}_{\text {pulse }}$ as described 281 in the Data Analysis Section of the SI, and the data are reported in Fig. 3. The Figure 282 reports $\mathrm{P}_{\max }$ values that are 3-5 times higher compared to the highest values obtained 283 during conventional MFC operations that with the same configuration were equal to 2 $284 \mathrm{Wm}^{-2}$ (BOx) (Santoro et al., 2013), $1.67 \mathrm{Wm}^{-2}$ (Fe-AAPyr) (Santoro et al., 2015b) and $2851.17 \mathrm{Wm}^{-2}$ (AC) (Santoro et al., 2015b) referred to the geometric area of the cathode, the 286 limiting electrode.

287 Fig. 3 even indicates that the MFCs can deliver pulse currents up to $4 \mathrm{~mA}$ (AC and Fe288 AAPyr) and $5 \mathrm{~mA}(\mathrm{BOx})$. We calculated that the highest $\mathrm{P}_{\text {pulse }}$ of $1.47 \mathrm{~mW}\left(6.53 \mathrm{Wm}^{-2}\right.$, $28911.76 \mathrm{Wm}^{-3}$ ) can be delivered by the BOx MFC at $3.7 \mathrm{~mA}$, followed by Fe-AAPyr-MFC $290\left(0.90 \mathrm{~mW}\left(4 \mathrm{Wm}^{-2}, 7.2 \mathrm{Wm}^{-3}\right)\right.$ at $\left.2.7 \mathrm{~mA}\right)$ and $\mathrm{AC}\left(0.67 \mathrm{~mW}\left(2.98 \mathrm{Wm}^{-2}, 5.36 \mathrm{Wm}^{-3}\right)\right.$ at $2912.2 \mathrm{~mA})$. 
292 Data in Table S1 and Fig. 3 demonstrate that the utilization of cathodes with high 293 working potentials is a reasonable option to increase the electric work and the power 294 output of the designated current pulse.

\section{3.2 MFC-AdC Response}

297 ESR, C, $i_{\text {pulse }}$ and $t_{\text {pulse }}$ are the key parameters to be optimized in order to achieve high 298 maximum energy $\left(E_{\max }\right)$ and power $\left(P_{\max }\right)$ and, more importantly, high practical values of 299 energy $\left(\mathrm{E}_{\text {pulse }}\right)$ and power $\left(\mathrm{P}_{\text {pulse }}\right)$ delivered during the pulses. The practical values of $\mathrm{E}_{\max }$ 300 and $\mathrm{P}_{\max }$ depend on the highest feasible cell voltage $\left(\mathrm{V}_{\max }\right)$, namely the voltage of the

301 charged cell in open circuit conditions $\left(\mathrm{V}_{\max }, \mathrm{OCV}\right)$ decreased by $\Delta \mathrm{V}_{\text {ohmic }}$ after the pulse, 302 which in turn depends on ESR and $i_{\text {pulse }}$ (see SI). ESR has to be minimized in order to 303 increase power output. The performance of the MFCs reported above was mainly 304 affected by the cathode ohmic losses. In order to overcome cathode limitation, an 305 additional cathode (denoted as AdC) was short-circuited with the MFC cathode,

306 embedded into the same electrolyte, and used as the positive electrode of the internal 307 supercapacitor (Fig. 1.b). The AdC was a carbon brush coated with activated carbon (AC)

308 to increase its surface area and electrode capacitance. The brush was used for its low 309 electrode resistance demonstrated in the previous section 3.1.

310 The AdC was short-circuited with the MFC cathode and it was brought to the high

311 potential value of the latter. This caused the formation of an electric double-layer at the

312 short-circuited brush/wastewater interface and the internal, positive charge of the AdC

313 (Fig. 1.b). Coupling the AdC with the MFC anode provides an internal, self-powered

314 EDLC that can be rapidly discharged by an electrostatic process to give high power 
315 output. According to the Kirchhoff law, the highest current will flow through the lowest

316 resistance branches of the circuit that models our system, i.e. the MFC anode and AdC

317 electrode resistances and the electrolyte resistance. The MFC cathode is then excluded

318 with positive effect on ESR and power output.

319 The MFC-AdC cells with AC, Fe-AAPyr and BOx cathodes short-circuited with the AdC

320 are labeled with AC-AdC, Fe-AAPyr-AdC, and BOx-AdC. Fig. 3 shows the cell voltage

321 and electrode potential profiles under $2 \mathrm{~s}$ discharge pulse at $3 \mathrm{~mA}$. The MFC-AdC

322 performances are summarized in Table S1.

323 Fig. 2 a, c, e demonstrate that the use of the $\mathrm{AdC}$ with $\mathrm{i}_{\text {pulse }}$ equal to $3 \mathrm{~mA}$ dramatically

324 decreases $\Delta \mathrm{V}_{\text {ohmic }}$ down to $66 \mathrm{mV}, 50 \mathrm{mV}$ and $56 \mathrm{mV}$ with AC, Fe-AAPyr and BOx

325 cathodes, without modifying the corresponding $V_{\max }$, oc. The MFC-AdC ESRs evaluated

326 by $\Delta \mathrm{V}_{\text {ohmic }}$ are 6-8 times lower than MFCs' and reduced to $16-22 \Omega$. Fig. $2 \mathrm{~b}$, d, f evinces

327 that this result is due to the very low potential losses of the AdC-short circuited cathodes,

328 in turn related to their low impedances of $\approx 13 \Omega$. Given that the cell capacitance did not

329 significantly change (except for the cell with Fe-AAPyr-AdC which exhibited $60 \mathrm{mF}$ ),

330 the time response $\tau$ was substantially lowered to $2 \mathrm{~s}$.

331 Table $\mathrm{S} 1$ demonstrates that the decreases of $\Delta \mathrm{V}_{\text {ohmic }}$ had the main effect on $\mathrm{V}_{\max }$ and on

332 energy and power values which substantially increased. The highest performance was

333 achieved with the BOx-AdC cell which at $3 \mathrm{~mA}$ featured a practical operation voltage of

$334734 \mathrm{mV}$ and $\mathrm{P}_{\text {pulse }}$ of $2 \mathrm{~mW}\left(\mathrm{t}_{\text {pulse }}=2 \mathrm{~s}\right)$. These are extremely high values that have never 335 been reported before for microbial fuel cells.

337 PLEASE INSERT HERE FIGURE 4 
339 The MFC-AdC cells were also tested at different pulse currents and the voltage profiles 340 analyzed to extract the $\mathrm{P}_{\max }$ vs $\mathrm{I}_{\text {pulse }}$ plots reported in Fig. 4 (see SI). The significant

341 decrease in ESR allow to achieve pulse current up to $45-50 \mathrm{~mA}$ that were roughly 10

342 times higher than the 4-5 mA possible with MFC. $\mathrm{P}_{\max }$ was $19 \mathrm{~mW}\left(84.4 \mathrm{Wm}^{-2}, 152 \mathrm{Wm}^{-}\right.$

$\left.343{ }^{3}\right)$ with BOx cathode, $14 \mathrm{~mW}\left(62.2 \mathrm{Wm}^{-2}, 112 \mathrm{Wm}^{-3}\right)$ with Fe-AAPyr and $6 \mathrm{~mW}(26.7$

$344 \mathrm{Wm}^{-2}, 49 \mathrm{Wm}^{-3}$ ) with $\mathrm{AC}$ cathode. These values are roughly one order of magnitude

345 higher than those achieved without AdC (Fig. 3), thus indicating the successful utilization 346 of the AdC.

\section{PLEASE INSERT HERE FIGURE 5}

350 Fig. 5 shows the MFC-AdC average pulse power $\mathrm{P}_{\text {pulse }}$ delivered at different currents over $35110 \mathrm{~ms}$ and $2 \mathrm{~s}$ pulses. Even under such test, the BOx-AdC cell outperformed the other 352 MFC-AdCs having $10 \mathrm{~ms}$ power output of $12 \mathrm{~mW}$, followed by $9.5 \mathrm{~mW}$ of Fe-AAPyr353 AdC and $4 \mathrm{~mW}$ of AC-AdC (Fig. 5.a). As it expected, the power decreases at pulse 354 length of $2 \mathrm{~s}$ and the highest $\mathrm{P}_{\text {pulse }}$ was $5 \mathrm{~mW}$ for BOx-AdC, followed by $3 \mathrm{~mW}$ for Fe355 AAPyr-AdC and $2 \mathrm{~mW}$ for AC-AdC (Fig. 5.b).

$357 \quad 3.3$ Supercapacitive recharging time and durability experiments 358

359 PLEASE INSERT HERE FIGURE 6 
361 Despite the higher OCP of the BOx, it has been shown previously that enzymes are not

362 durable for long period of time mainly due to denaturation or deactivation (Santoro et al.

363 2013). Moreover, currently, the cost of $\mathrm{BOx}$ is very high limiting practical utilization for

364 wastewater treatment purposes. At the contrary, Fe-AAPyr is a reliable catalyst for

365 oxygen reduction reaction at neutral $\mathrm{pH}$ due to its stability and low cost aiming to be a

366 good candidate for large-scale application (Santoro et al. 2015a). Consequently, the

367 recharging time and durability tests have been carried out considering the MFC-AdC with

368 Fe-AAPyr cathode for possible real and long terms application.

369 Fig. 6.a shows the voltage and electrode potential profiles of the Fe-AAPyr-AdC cell

370 under an OC-GLV-OC sequence with 2s-pulses at $6 \mathrm{~mA}$ and $20 \mathrm{~s}$ rest. The rest of $20 \mathrm{~s}$

371 was enough to restore the equilibrium electrode potentials and "recharge" the cell at the

$372 \mathrm{~V}_{\max }$, oc voltage (Fig. 6.b). Each cycle overlapped indicating the reversibility of the

373 process. This underlines that the self-recharge of the internal EDLC is reversible and fast

374 and can take place in the order of seconds.

375 The cycling stability of the Fe-AAPyr-AdC was proved over 1000 OC-GLV-OC steps

376 which were performed by $10 \mathrm{~ms}-$ pulses at $10 \mathrm{~mA}$ followed by $10 \mathrm{~s}$ rest. The first four

377 (Fig. S1c) and last four (Fig. S1d) cycles are also reported. The cell voltage as well as the

378 anodic and cathodic potentials during the initial and final cycles had very similar trend

379 thus indicating that high current regimes $(10 \mathrm{~mA})$ do not affect the performances of the

380 cell. Equilibria anode and cathode potentials are recovered in few seconds and this 381 permits a stable, long-time operation. 
385 In this first proof of concept, we demonstrate that current/power output is comparable 386 with MFC/external supercapacitor systems' with the advantage of much shorter

387 recharging time: sec/min instead of hours. This permits to increase power output

388 frequency that is an appealing feature for real applications where devices need to be

389 frequently powered. Notably, the AdC size can be independently sized which makes it 390 possible to de-couple energy and power and to address target application requirements,

391 from sensor to external pump powering for self-sustainable systems. At last, the proposed

392 concept is sustainable in terms of materials, processes and energy cost. Further works

393 will be addressed to cell design and materials optimization for system scaling up.

394

\section{4. Conclusions}

397 To the best of our knowledge, for the first time a supercapacitive system with MFC anode 398 and cathode used as negative and positive electrodes of a self-rechargeable, internal 399 supercapacitor is demonstrated. The use of high voltage operation cathodes and the 400 additional capacitive cathode electrode permitted to achieve the exceptionally high power 401 of $19 \mathrm{~mW}$ under pulse currents as high as $45 \mathrm{~mA}$. The power normalized to the geometric 402 cathode area results $84 \mathrm{~W} \mathrm{~m}^{-2}$. This is the highest performance ever achieved by an MFC 403 system. With respect to MFC/external supercapacitor coupling, MFC-AdC is a more 404 efficient, simple and cheap way of harvesting energy from the MFC system and does not 405 require any additional electronics management. 
409 This project was funded by the Electrochemical Society and Bill \& Melinda Gates

410 Foundation under initiative: "Applying Electrochemistry to Complex Global

411 Challenges". FS and CA acknowledge financial support by Alma Mater Studiorum -

412 Università di Bologna (Researcher Mobility Program).

413

414 References

415 Agnès, C., Holzinger, M., Le Goff, A., Reuillard, B., Elouarzaki, K., Tingry, S., Cosnier 416 S., 2014. Energy Environ. Sci. 7, 1884-1888

417 Antolini, E., 2015. Biosens. Bioelectron. 69, 54-70.

418 Béguin, F., Presser, V., Balducci, A., Frackowiak, E., 2014. Carbons and electrolytes for 419 advanced supercapacitors. Adv. Mater. 26(14), 2219-2251

420 Conway, B.E., 199. Electrochemical Supercapacitors: Scientific Fundamentals and 421 Technological Applications, Springer.

422 Deeke, A. Sleutels, T.H.J.A., Hamelers, HV.M., Buisman, C.J.N., 2012. Environ. Sci. 423 Technol. 46(6), 3554-3560

424 Dewan, A., Ay, S.U., Karim, M.N., Beyenal, H., 2014. J. Power Sources, 245, 129-143

425 Di Lorenzo, M., Thomson, A.R., Schneider, K., Cameron, P.J., Ieropoulos, I., 2014. 426 Biosens. Bioelectron. 62, 182-188

427 Donovan, C., Dewan, A., Peng, H., Heo, D., Beyenal, H., 2011. J. Power Sources, $428 \quad 196(3), 1171-1177$ 
429 Donovan, C., Dewan, A., Heo, D., Lewandowski Z., Beyenal, H., 2013. J. Power $430 \quad$ Sources, 233, 79-85.

431 Erable, B., Féron, D., Bergel, A., 2012. ChemSusChem 5(6), 975-987

432 Ewing, T., Ha, P.T., Babauta, J.T., Tang, N.T., Heo, D., Beyenal, H., 2014. J. Power $433 \quad$ Sources 272, 311-319.

434 Feng, C., Lv, Z., Yang, X., Wei, C. Anode modification with capacitive materials for a 435 microbial fuel cell: an increase in transient power or stationary power, PCCP, 16 $436 \quad$ (2014) 10464-10472

437 Guerrini, E., Cristiani, P., Grattieri, M., Santoro, C., Li, B., Trasatti, S., 2014. J. 438 Electrochem. Soc. 161 (3), H62-H67

439 Higgins, S.R., Lau, C., Atanassov, P., Minteer, S.D., Cooney, M.J., 2011. ACS Catal., 1 $440 \quad(9), 994-997$

441 Ieropoulos, I., Melhuish, C., Greenman J., Horsfield, I., 2005. Journal of Advanced $442 \quad$ Robotic Systems, 2(4), 295-300

443 Ieropoulos, I., Greenman, J., Melhuish C., Horsfield, I., 2010. EcoBot-III-A Robot with $444 \quad$ Guts. ALIFE, 733-740.

445 Ieropoulos, I.A., Greenman, J., Melhuish, C., Horsfield, I., 2012. ChemSusChem $446 \quad 5(6), 1020-1026$

447 Ieropoulos, I.A., Ledezma, P., Stinchcombe, A., Papaharalabos, G., Melhuish, C., 448 Greenman, J., 2013. Phys. Chem. Chem. Phys. 15(37), 15312-15316

449 Ishii, S., Suzuki, S., Norden-Krichmar, T.M., Phan, T., Wanger, G., Nealson, K.H., 450 Sekiguchi, Y., Gorby Y.A., Bretschger, O., 2014. ISME J., 8(5), 963-978 
451 Jang, J.K., Kan, J., Bretschger, O., Gorby, Y.A., Hsu, L., Kim, B.H., Nealson, K.H., 452 2013. J. Microbiol. Biotechnol. 23(12), 1765-1773.

453 Ledezma, P., Stinchcombe, A., Greenman J., Ieropoulos, I., 2013. Phys. Chem. Chem. $454 \quad$ Phys. 15, 2278-2281

455 Liu, X.-W., Li, W.-W., Yu, H.-Q., 2014. Chem. Soc. Rev., 43, 7718-7745

456 Logan B.E., Rabaey, K., 2012. Science 337, 686-690

457 Lv, Z., Xie, D., Yue, X., Feng C., Wei, C., 2012. J. Power Sources 210, 26-31

458 Mano, N., Fernandez, J.L., Kim, Y., Shin, W., Bard, A.J., Heller, A., 2003. J. Am. Chem. $459 \quad$ Soc. $125(50), 15290-15291$

460 Pankratov, D., Falkman, P., Blum Z., Shleev, S., 2014a. Energy Environ. Sci., 7, 989461993

462 Pankratov, D., Blum, Z., Suyatin, D.B., Popov V.O., Shleev, S., $2014 b$. 463 ChemElectroChem 1(2), 343-346.

464 Papaharalabos, G., Greenman, J., Melhuish, C., Santoro, C., Cristiani, P., Li, B., 465 Ieropoulos, I., 2013. Int. J. Hydrogen Energy 38(26), 11552-11558

466 Papaharalabos, G., Greenman, J., Stinchcombe, A., Horsfield, I., Melhuish, C., 467 Ieropoulos, I., 2014. J. Power Sources, 272, 34-38

468 Park, J.-D., Ren, Z.J., 2012. J. Power Sources 208, 322-327.

469 Pocaznoi, D., Calmet, A., Etcheverry, L., Erable, B., Bergel, A., 2012. Energy Environ. $470 \quad$ Sci., $5,9645-9652$

471 Rinaldi, A., Mecheri, B., Garavaglia, V., Licoccia, S., Di Nardo, P., Traversa, E., 2008.

$472 \quad$ Energy Environ. Sci., 1, 417-429 
473 Santoro, C., Babanova, S., Atanassov, P., Li, B., Ieropoulos, I., Cristiani, P., 2013. J. $474 \quad$ Electrochem. Soc. 160(10), H720-H726

475 Santoro, C., Artyushkova, K., Babanova, B., Atanassov, P., Ieropoulos, I., Grattieri, M., 476 Cristiani, P., Trasatti, S., Li, B., Schuler, A.J., 2014. Biores. Technol. 163, 54-63

477 Santoro, C., Serov, A., Narvaez Villarrubia, C.W., Stariha, S., Babanova, S., Schuler, A., 478 Artyushkova, K., Atanassov, P., 2015a. ChemSusChem 8(5), 828-834

479 Santoro, C., Serov, A., Narvaez Villarrubia, C.W., Stariha, S., Babanova, S., 480 Artyushkova, K., Schuler, A., Atanassov, P., 2015b. Sci. Rep. In press.

481 Schaetzle, O., Barrière F., Schröder, U., 2009. Energy Environ. Sci. 2, 96-99.

482 Serov, A., Artyushkova, K., Atanassov, P., 2014a. Adv. Energy Mater., 4, 1301735 doi: $483 \quad 10.1002 /$ aenm.201301735.

484 Serov, A., Tylus, U., Artyushkova, K., Mukerjee, S., Atanassov, P., 2014b. Appl. Catal., $485 \quad$ B, $150,179-186$

486 Soukharev, V., Mano, N., Heller, A., 2004. J. Am. Chem. Soc. 126(27), 8368-8369

487 Wang, H., Park, J., Ren, Z.J., 2015. Environ. Sci. Technol. 49, 3267-3277

488 Watson, V.J., Delgado, C.N., Logan, B.E., 2013. Environ. Sci. Technol., 47(12), $489 \quad 6704-6710$

490 Wei, J., Liang, P., Huang, X., 2011. Biores. Technol. 102, 9335-9344 


\section{Figures Content}

Figure 1. Microbial Fuel Cell configuration with anode and cathode of the MFC used as EDLC electrodes. Red and blue circles indicate cations and anions, respectively (a). MFCAdC configuration with short circuited AdC-cathode and anode of the MFC used as EDLC electrodes (b). Current/Cell Voltage trends during the OC - GLV- OC sequence used for the electrochemical test. The labels indicate the parameters used for the evaluations of the system performance (c).

Figure 2. Cell voltage $(\mathrm{a}, \mathrm{c}, \mathrm{e})$ and electrode potential $(\mathrm{b}, \mathrm{d}, \mathrm{f})$ profiles of MFC and MFCAdC cells with AC (a,b), Fe-AAPyr $(c, d)$ and BOx $(e, f)$ cathodes under $5 \mathrm{~s}$ rest and $2 \mathrm{~s}$ pulses at $3 \mathrm{~mA}$.

Figure 3. Calculated $\mathrm{P}_{\max }$ vs. $\mathrm{i}_{\text {pulse }}$ plots of the MFCs assembled with $\mathrm{AC}, \mathrm{BOx}$ and FeAAPyr cathodes.

Figure 4. $P_{\max }$ vs. $i_{\text {pulse }}$ plots of the three MFCs having the additional cathode calculated at different pulse currents.

Figure 5. $\mathrm{P}_{\text {pulse }}$ vs. $\mathrm{i}_{\text {pulse }}$ plots for MFC-AdC cells for pulse time of $10 \mathrm{~ms}$ (a) and $2 \mathrm{~s}$ (b).

Figure 6. Cell voltage (a) and anode and cathode potentials (b) profile of a Fe-AAPyr-AdC cell under an OC-GLV-OC sequence with 2s-pulses at $6 \mathrm{~mA}$ and $20 \mathrm{~s}$ rest. 
Figure 1
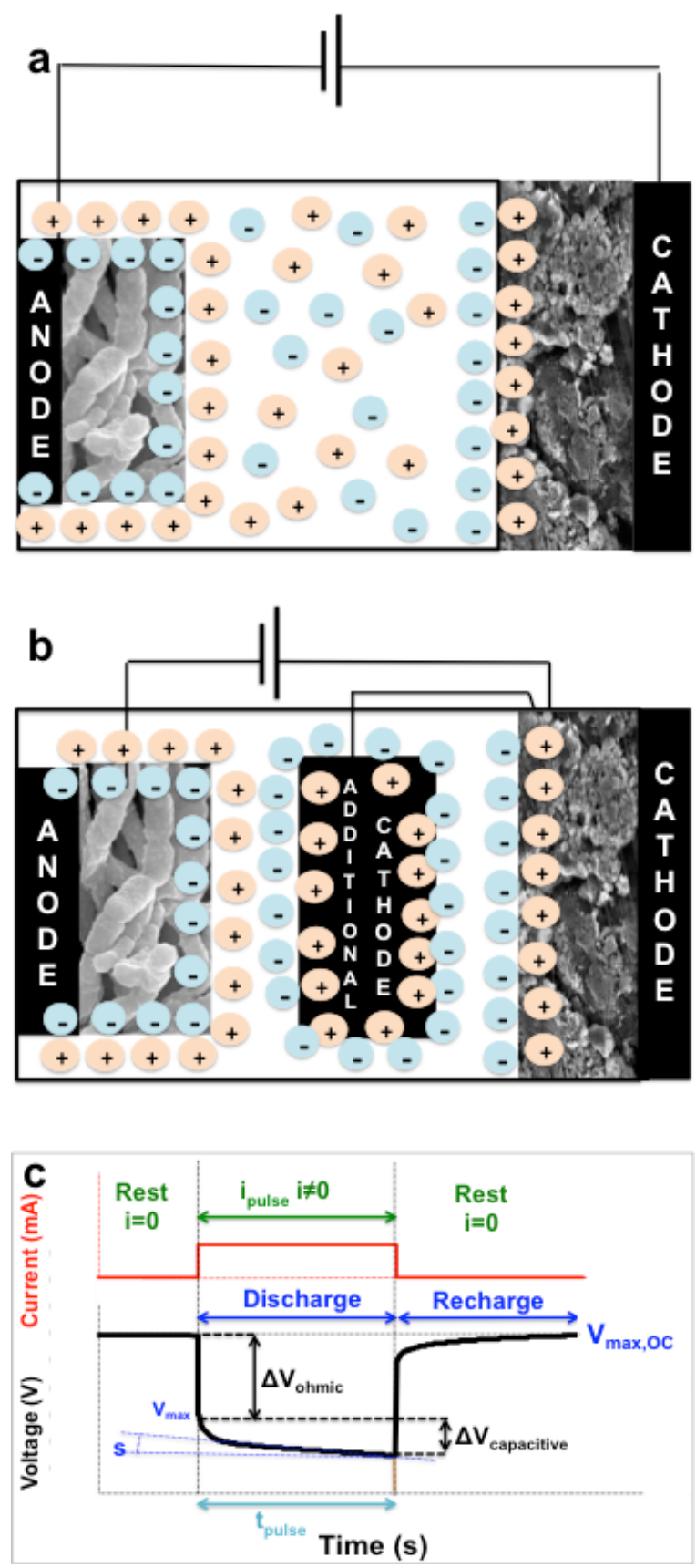

Figure 2
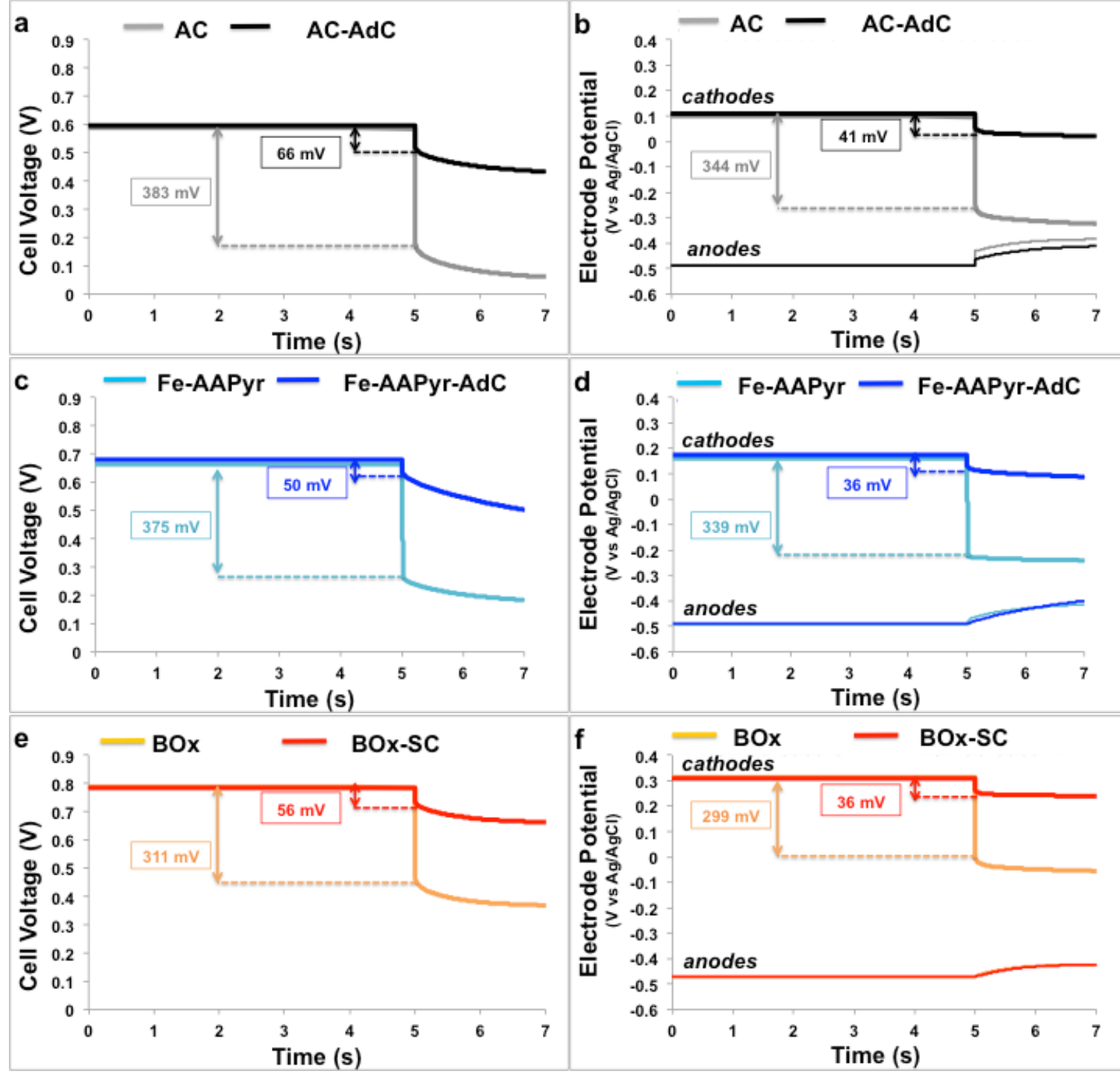
Figure 3

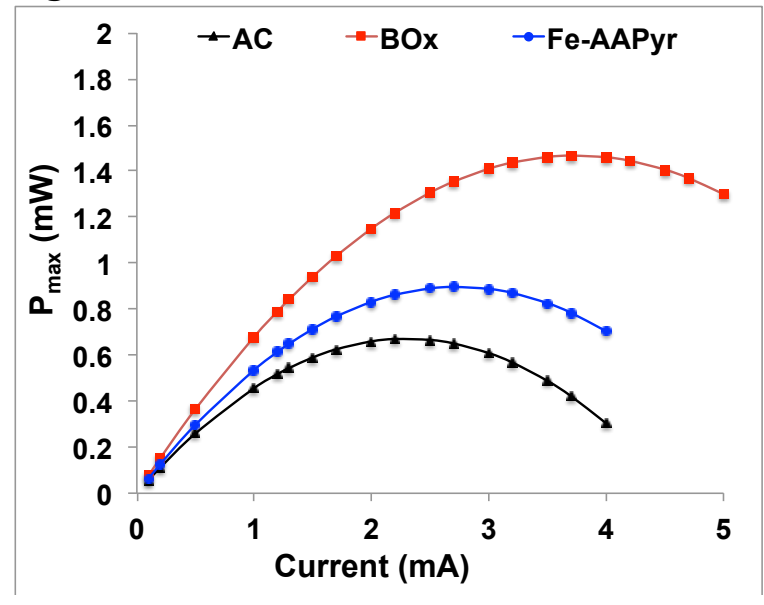

Figure 4

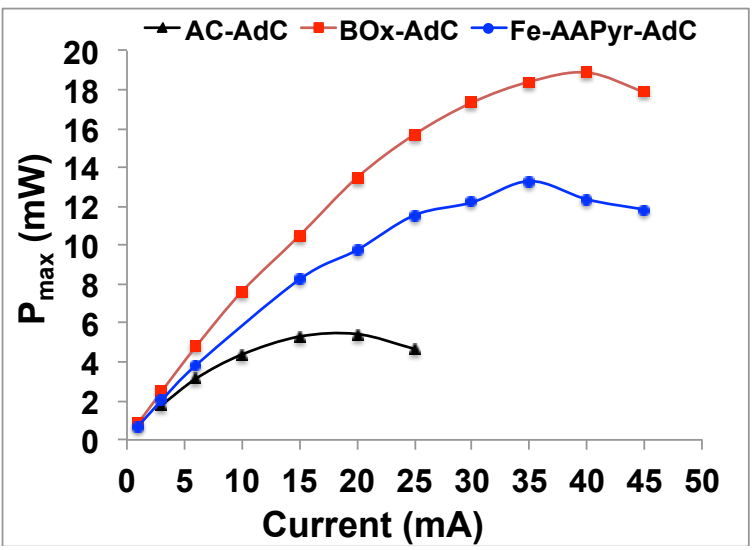


Figure 5
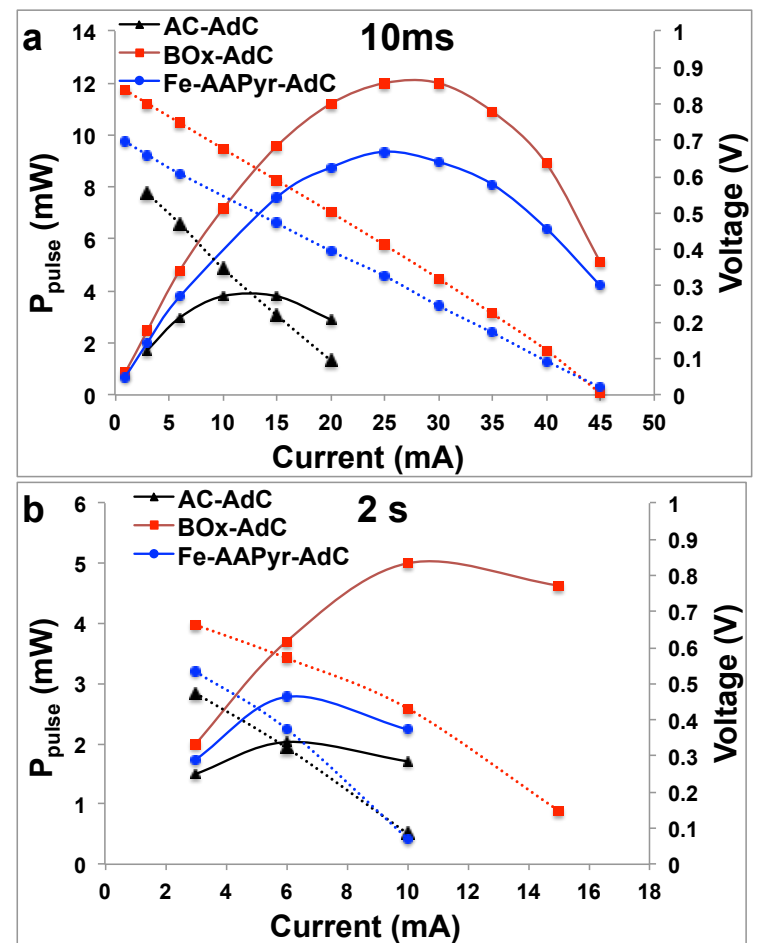
Figure 6
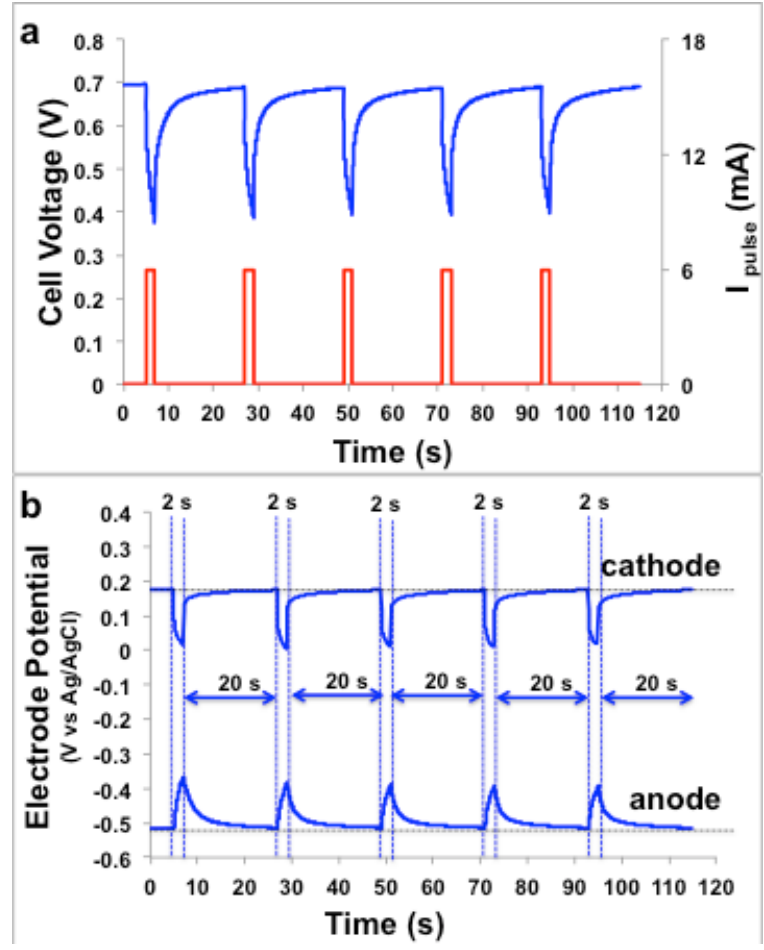